\title{
Tıp Öğrencilerinin Tıpta Uzmanlık Tercihlerini Etkileyen Faktörler Üzerine Sistematik Derleme ${ }^{1}$
}

\begin{abstract}
DOI: 10.26466/opus.646193
İbrahim Hüseyin Cansever* - Aslı Metin** - Merve Kişi***

* Doktora Öğr., Süleyman Demirel Üni. Sosyal Bil. Ens., Sağlık Kurumları Yön. A.B.D., Isparta/Türkiye E-Posta: ihcansever@hotmail.com

ORCID: 0000-0002-9999-6789

** Arş. Gör., Süleyman Demirel Üniversitesi, İ.İ.B.F, Sağlık Yönetimi Böl., Isparta/Türkiye

E-Posta: aslivergili@sdu.edu.tr

ORCID: 0000-0002-6967-1772

*** Arş. Gör., Süleyman Demirel Üniversitesi, İ.İ.B.F, Sağlık Yönetimi Böl., Isparta/Türkiye

E-Posta: merveuysal@sdu.edu.tr

ORCID: $\underline{0000-0001-9226-8490}$

\section{Öz}

Çalışmanın amacı, zamanla değişen uzmanlik alan tercihleri ve bunları etkileyen nedenlerin ortaya konulabilmesi için Türkiye'de eğitim alan tıp öğrencilerinin uzmanlık tercihini etkileyen faktörleri ortaya çıarmayı amaçlayan çalışmalar derleyerek genel bir değerlendirmesini yapmak ve elde edilen sonuçlara ilişkin olarak kanıta dayalı bir politika önerisi geliştirmektir. Çalışmada sistematik derleme yöntemi kullanılmıştır. Amaca yönelik olarak ULAKBIM, Google Akademik, Science Direct veri tabanlarinda "Tipta Uzmanlik Sinavı", "Öğrenci" ve "Türkiye" anahtar kelimeleri Türkçe ve İngilizce dilinde kullanılarak gerekli taramalar yapılmuş ve belirlenen kriterlere uyumlu olan 9 adet çalısma derlemeye dâhil edilmiştir. Derlemede, tıp öğrencilerinin tercihlerini etkileyen faktörler araştırılmış ve birçok faktörün öğrencilerin uzmanlık tercihini etkilediği ortaya çıkmıştır. Ortaya çıkan faktörler, uzmanlık eğitimi öncesi ve uzmanlık eğitimi sonrası olarak kategorilendirilmiştir. Bu kategorilendirme hem sonuçları daha net görmeyi hem de çözüm önerileri oluşturma yolunda kolaylık sağlamıştır. Uzmanlık eğitimi öncesi süreçte tercihleri en fazla etkileyen faktörler olarak; uzmanlık dalına olan ilgi/yetenek, toplumun algısı/bakışı ve aile isteği/baskısı şeklinde ortaya çıkmıştır. Uzmanlık eğitimi sonrası süreçte ise tercihleri en çok etkileyen faktörler; maddi tatmin, çalışma koşulları (nöbet sayısı, çalışma saatleri, kolay olması) akademik kariyer firsatı, mesleki tatmin, kişisel gelişim ve kariyer şansı ve malpraktis şeklinde ortaya çıkmıştır. Derlemede ele alınan çalısmaların birbirleriyle çeşitli yönlerden benzerlik gösterdiği ancak hem kapsam hem de içerik yönünden farklllaştı̆̆ı görülmüştür.
\end{abstract}

Anahtar Kelimeler: TUS, Tıpta Uzmanlık Eğitimi, Meslek Seçimi, Kariyer Planı, Sistematik Derleme

\footnotetext{
${ }^{1}$ Bu çalışma 10-13 Ekim 2019 tarihinde gerçekleşmiş olan 3. Uluslararası 13. Ulusal Sağlık ve Hastane idaresi Kongresinde sözlü bildiri olarak sunulmuş, kongre tam metin kitabında yayımlanmıştır. Çalışma kongrede alınan geri bildirimlerle birlikte revize edilerek düzenlenmiştir.
} 


\title{
Systematic Review On Factors Affecting Medical Students Preferences In Medical Specialization
}

\begin{abstract}
The aim of this study is to determine how medical students' preferences in specialty in medicine change over time. Studies involving this subject has been compiled about the medical students in Turkey, to determine what factors affecting preferences in speciality in medicine. Thus, an overall assessment will be made and an evidence-based policy proposal will be developed regarding the results obtained. Systematic review method was used in this study. For this purpose in Turkish and English languages, ULAKBIM, Google Scholar, Science Direct database in "Examination for specialty in medicine", "Student" and "Turkey" search using keywords have been made. Nine studies compatible with the determined criteria were included in the review. In this review, the factors affecting the preferences of medical students were investigated and it was found that many factors affected the preferences of the students. The result factors were categorized as "before specialty education in medicine" and "after specialty education in medicine". This categorization has made it easier to see the results more clearly and to propose solutions. Before specialty education in medicine process, as the most influential factors of the preferences of specialty, interest / talent in the field of specialization, perception / view of society and family desire / pressure has ben determined. After specialty education in medicine, as the most influential factors of preferences in specialty, financial satisfaction, working conditions (number of shift, working hours, ease of working), academic career opportunity, professional satisfaction, personal development, career chance and malpractice has ben determined. It was observed that the studies discussed in the review have similarities with each other in various aspects, but differed in terms of both scope and content..
\end{abstract}

Keywords: TUS, Medical Specialty Education, Career Selection, Career Plan, Systematic Rewiev 


\section{Giriş}

Meslek seçimi, kişinin hayatındaki en önemli aşamalardan biri olarak meslek grupları arasından kişinin kendine maddi ve manevi yönden doyum sağlayacağını düşündüğü mesleğe yönelmesidir (Brown, 2002, s.48). Hekimlik mesleği, üniversitelerin tıp fakültelerinde verilen altı yıllık tıp eğitimi sonrası alınan tıp doktoru unvanı sonucu icra edilebilen meslektir. Bu unvan sonrası iki seçenek mevcuttur. Birincisi pratisyen hekimliktir ve devlet hizmet yükümlülüğü kurasına girerek zorunlu görev yapmak şartiyla (Sağlık Hizmetleri Temel Kanunu, 2005: Ek Madde 1, 5) birinci basamak sağlık kuruluşlarında aile hekimliği, özel sağlık kuruluşlarında veya işyeri hekimliği gibi uzmanlık gerektirmeyen yerlerde hekimlik görevi yerine getirilebilmektedir.

Tip doktoru unvanının alınması sonrası bir diğer alternatif de Tipta Uzmanlık Sınavı (TUS)'na girip, sınav sonucuna ve isteğine göre seçtiği alanda uzmanlık eğitimi alarak uzmanlaşmasıdır. TUS, ülkemizde 1987 yılından bugüne kadar her yıl düzenli olarak yapılmaktadır. TUS, 1219 sayılı Tababet ve Şuabatı San'atlarının Tarzı İcrasına Dair Kanun'un 26.04.2014 tarihli ve 28983 sayılı Resmî Gazete'de yayımlanarak yürürlüğe giren Tıpta ve Diş Hekimliğinde Uzmanlık Eğitimi Yönetmeliği, Yükseköğretim Kanunu ve ilgili yönetmeliklerin hükümleri çerçevesinde Ölçme, Seçme ve Yerleştirme Merkezi Başkanlığı (ÖSYM) tarafından yürütülmektedir (ÖSYM, 2019, s.1). Şubat ve Eylül aylarında olmak üzere yılda iki kere düzenlenen bu sınav uzmanlık eğitimi almak isteyen hekimler için hayati öneme sahiptir. Sınavın tanımı ve içeriği ile ilgili olarak ÖSYM Tıpta Uzmanlık Eğitimi Giriş Sınavı Başvuru Kılavuzu'nda; "Yeterlik ve yarışma esaslarına dayanan uzmanlık eğitimi giriş sınavlarında adayların, tıp alanındaki temel kavram, ilke ve yöntemleri tanıma, kavrama; bu kavram, ilke ve yöntemler ile düşünme ve bunları belli durumlara uygulama yetilerini yoklayan sorular bulunacaktır. Mesleki Bilgi Sınavının amacı bu sınav sonucuna göre tıpta uzmanlık eğitimine kabul edilecek adayları seçerek tercihlerine göre mevcut kontenjanlara yerleştirmektir." şeklinde belirtilmiştir (ÖSYM, 2019, s.1). Sınav, Temel Tip Bilimleri ve Klinik Tıp Bilimleri olmak üzere iki ayrı bölümden oluşmaktadır. Adaylar tercihlerine göre üniversitelerin Tıp Fakülteleri, Sağlık Bakanl1ğ1 Eğitim ve Araştırma Hastaneleri veya Adli Tıp Kurumu'nda eğitim alabilmektedirler (Kaya vd., 2014, s.54). TUS, tıp fakültelerinden mezun hekim- 
ler için oldukça önemli olmakla birlikte günümüzde tıp fakültelerinin ve dolayısı ile kontenjanların artması ve uzmanlık kadrolarının sınırlı kalması gibi birçok faktörden etkilenmektedir.

TUS sonrası yapılan tercih ile kişiler puanlarına göre uzmanlık alanlarına yerleştirilmektedir. Uzmanlık eğitiminde bazı branşlar birbirinden çok farklı özellikler içerebilirken bazı branşlar birbirine daha yakın özellikler barındırmaktadır (Yoney ve Gogas-Yavuz, 2010, s.10). Bunun yanında eğitim süreleri de branşlar arasında farklılıklar göstermektedir. Örneğin, Sağlık Bakanlığı Tıpta Uzmanlık Kurulu kararı ile Üroloji uzmanlığı eğitim süresi 5 yıl, Nefroloji uzmanlığı eğitim süresi 3 yıl iken El Cerrahisi Uzmanlı̆̆ eğitimi 2 yıldır (Sağlık Bakanlığı Tıpta Uzmanlık Kurulu, 2018, s.2-4). Bu eğitim sonrası uzman doktor unvanı alan kişiler mecburi hizmetlerini tamamlamaları sonrası devlet hastaneleri veya özel hastanelerde görev yapabilmektedir.

Öğrencilerin tercihlerini birçok faktör etkilemektedir. Bu kapsamda, profesyonel motive edici faktörler psikolojide; toplum temelli faktörler (prosocial), içsel faktörler (internal), dışsal faktörler (external) ve kaytarma (loafing) olarak dört başlıkta incelenmektedir. Bunlardan toplum temelli faktörler kişinin topluma faydalı işler yapma veya topluma yarar sağlama yoluyla tatmin olmasını içerir. Dışsal faktörler, maddi getiri veya başarı faktörü gibi tatminleri içerir. İçsel faktörler, daha çok kişinin ilgi ve motivasyonu gibi olguları içerir. Son olarak kaytarma ise kişinin hedeflerine en kolay yoldan ulaşmak için yaptığı faaliyetlerdir (Heckhausen, 1977, s.285-287; Skatova ve Ferguson, 2014, s.2).

Çalışmanın amacı, zamanla değişen uzmanlık alan tercihleri ve bunları etkileyen nedenlerin ortaya konulabilmesi için, Türkiye'de eğitim alan tıp öğrencilerinin uzmanlık tercihini etkileyen faktörleri ortaya çıkarmayı amaçlayan çalışmaları derleyerek genel bir değerlendirmesini yapmak ve elde edilen sonuçlara ilişkin olarak kanıta dayalı bir politika önerisi geliştirmektir.

\section{Yöntem}

Çalışmada sistematik derleme yöntemi kullanılmıştır. Derlemede konuya ilişkin olan çalışmalar, TUS'un yapılmaya başlandığı 1987 yılı ile 2019 (ilk 6 ay) yılları arasında, tıp öğrencilerinin uzmanlık tercihlerini etkileyen faktör- 
lere yönelik olarak yapılmış çalışmalar ele alınmıştır. İlgili çalışmaları elde etmek için ULAKBIMM, Google Akademik, Science Direct veri tabanlarında “Tıpta Uzmanlık Sınavı”, “Öğrenci” ve “Türkiye” anahtar kelimeleri Türkçe ve İngilizce dilinde kullanılarak gerekli taramalar yapılmıştır.

\section{Çalışmaya Dâhil Edilme Kriterleri}

Çalışmaya dahil edilme kriterleri, hakemli dergide yayımlanmış olmak, kantitatif özellikte olmak, örneklem grubunda tı öğrencilerinin olması ve mezuniyet sonrası döneme ilişkin uzmanlık tercihlerini içermek şeklinde belirlenmiştir. Bu kapsamda yüksek lisans, doktora ve uzmanlık tezleri derlemenin kapsamı dışında tutulmuştur. Veri taramalarına ilişkin akış şeması Şekil 1'de gösterilmiştir.

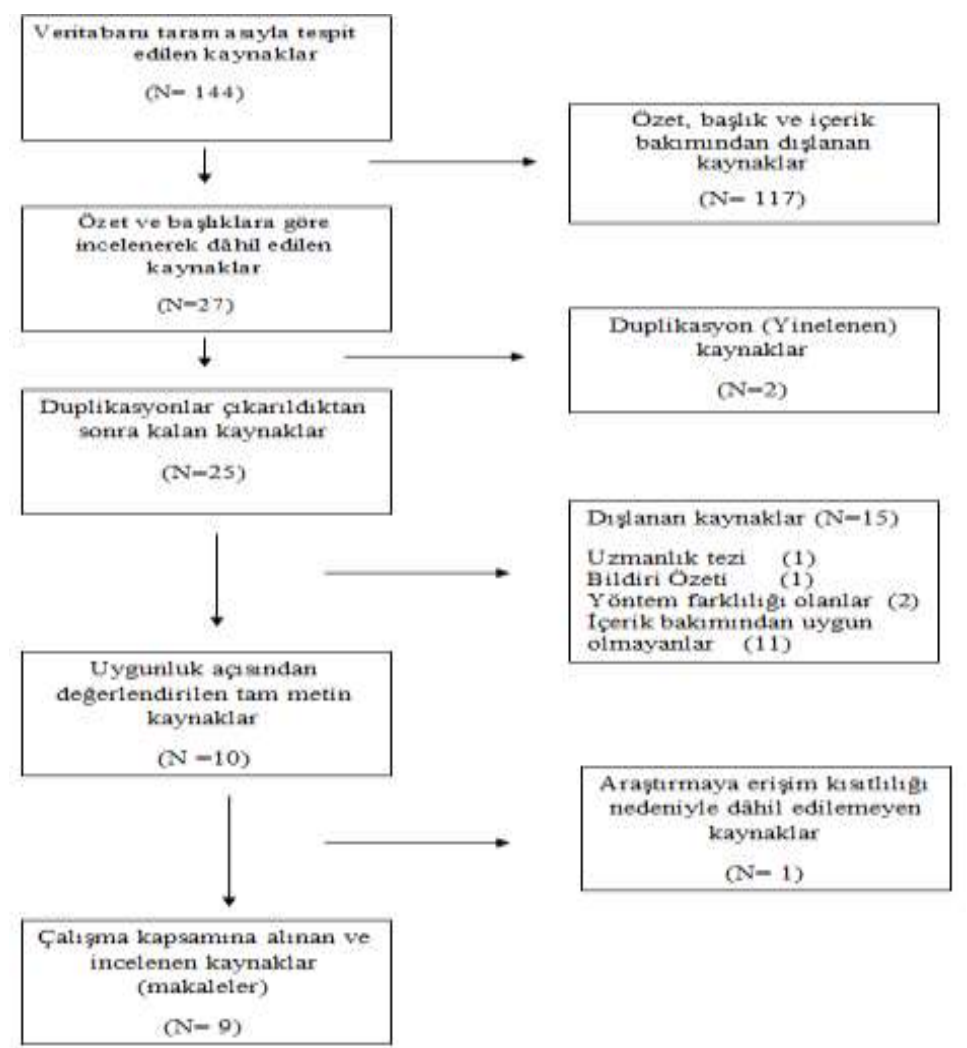

Şekil 1. Derlemeye İlişkin Veri Tarama Akış Şeması 
Toplam 144 kaynağa ulaşılmış olup; bunlardan 117 tanesi başlık ve özet incelemesi sonucu konu ile ilgili olmadığı saptanmış ve dâhil edilmemiştir. Kalan 27 makalede, 2 adet duplikasyon olduğu için çıkarılmıştır. Geriye kalan 25 makaleden 15 tanesi dâhil edilme kriterlerine uymadığ 1 için (1 adet uzmanlık tezi, 1 adet bildiri özeti, 2 adet yöntem farklılığı ve 11 adet içerik ve amaç farklılığı) kapsam dışında bırakılmıştır. Şemada belirtilen yöntem farklılığından kasıt, dahil edilme kriterlerinde de belirtilen kantitatif özellik taşımamasıdır. İçerik ve amaç bakımından farklılıklar ise, dahil edilmeyen çalışmaların belirli bir uzmanlık alanına ilişkin olması ve değerlendirme çalışması niteliği taşımasıdır. 1 adet çalışmanın da tam metnine ulaşılamadığı için kapsam dışında kalmıştır. Ulaşılamayan makale ise 2008 yılında yayımlanmış olan "Hacettepe Üniversitesi Dönem VI Öğrencilerinin Tipta Uzmanlık Sınavı (TUS) Hakkındaki Görüşleri" isimli çalışmadır. Geriye kalan 9 adet çalışma derleme kapsamında ele alınmıştır.

\section{Değerlendirme Yöntemi ve Analizi}

Ele alınan 9 tane çalışmanın kalite değerlendirmesinde, Polit ve Beck (2009, s.169-193) tarafından önerilen, değerlendirme ölçütlerinden on iki adet kullanılmıştır. Çalışmaların kalitesini değerlendirmede kullanılan ölçütler şunlardir;

1. Araştırmanın amacı ve araştırma soruları uygun biçimde sunulmuş $\mathrm{mu}$ ?

2. Araştırma soruları uygun biçimde yanıtlanmış mı?

3. Çalışmada geçen kavramlar açıkça tanımlanmış mı?

4. Örneklemin özellikleri yeterince açılanmış mı?

5. Örneklem sayısı yeterli mi?

6. Kullanılan gereç ve yöntem konuya uygun mu?

7. Kullanılan gereç geçerli ve güvenilir mi?

8. Bulgular açık ve uygun biçimde organize edilmiş mi?

9. Bütün önemli sonuçlar tartışılmış mı?

10. Tartışma bulgularla uyumlu mu?

11. Sonuçlar özet olarak bildirilmiş mi?

12. Sınırlılıklar bildirilmiş mi? (Polit ve Beck, 2009, s.169-193).

Her çalışma 12 ölçüt üzerinden tüm yazarlar tarafından değerlendirilerek karşılama durumunda " 1 ", karşılamama durumunda ise "0" puan veri- 
lerek toplam bir değer almıştır. Bu değerlendirme sonucu yazarlar tarafından çalışmalara; en yüksek 11 ve en düşük 8 puan verilmiş ve puan ortalamaları sonraki bölümde Tablo 1'de sunulmuştur. Bunun yanında yazarlar arasındaki uyumun ortaya çıkarılması için SPSS programında uyum analizi yapılmış ve kappa değeri 0,561 olarak bulunmuştur. Kappa değerinin hesaplanması sürecinde ikiden fazla planlayıcı olması durumunda kullanılan Fleiss'in kappa katsayısı hesaplamasından faydalanılmışır. Fleiss tarafından yapılan sınıflamada değerin 0.75 ve üzeri olması mükemmel, 0.40-0.75 arası orta-iyi, 0.40 'ın altında olması ise uyumu zayıf olarak değerlendirilmiştir (Kılıç, 2015, s.142-143; Fleiss, 2003: s.604-607; Landis ve Koch, 1977, s.165). Bu kapsamda ortaya çıkan 0,561 değeri Fleiss'in tanımına göre 0,40-0,75 kategorisinde yer almakta ve puanlayıcılar arasında uyumun orta-iyi olduğunu göstermektedir.

\section{Bulgular}

Derleme bulguları sunulmadan önce inceleme kapsamına alınan çalışmaların özellikleri (yazarlar, çalışma adı, amacı, kapsamı), sonuçları ve kalite değerlendirme puan ortalamalarını içeren Tablo 1 hazırlanmıştır. Tabloda görüldüğü üzere, çalışmalardan en eski tarihli olanı 1999 yılında en yeni tarihli olanı ise 2019 yılında yayımlanmıştır. Çalışmaların tamamında araştırma yöntemi olarak Kesitsel araştırma (Cross-section) kullanılmıştır. Çalışmalardan 3 tanesi İngilizce, 6 tanesi Türkçe dilinde yazılmıştır. Seçilen çalışmaların hepsinde, dâhil edilme kriterlerinde de belirtildiği üzere araştırma grubu tıp fakültesi öğrencilerinden oluşmuştur. En az örneklem say1sina sahip çalışmada 101 öğrenci (Kara vd., 2014), en fazla örneklem sayısı ise 1.340 öğrenci (Köksal vd., 1999) oluşturmuştur.

Çalışmalardan sekiz tanesi yalnızca bir üniversitede yürütülürken, bir tanesi (Dikici vd., 2008) dört farklı üniversitede yürütülmüştür. Derlemeye alınan çalışmaların tamamının içinde tıp fakültesi öğrencilerinin mezuniyet sonrası uzmanlık tercihlerini etkileyen faktörlere ilişkin açıklamalar yer almaktadır. Derleme kapsamındaki çalışmalar yazarlar tarafından kalite değerlendirmesine tabi tutulmuş ve ortalamalar; en düşük 8,0 en yüksek 11,3 olarak ortaya çıkmıştır. 
Tablo 1. İncelenen Çalışmalarn Özellikleri ve Sonuçlar

\begin{tabular}{|c|c|c|c|c|c|}
\hline Yazarlar & Çalışmanın Adı & Çalışmanın Amacı & $\begin{array}{l}\begin{array}{l}\text { Örneklem Büyüklüğü } \\
\text { ve Kapsamı }\end{array}\end{array}$ & $\begin{array}{l}\text { Çalışmanın Uzmanlık Tercihleri- } \\
\text { ni Etkileyen Faktörlere ilişkin } \\
\text { Sonuçları }\end{array}$ & $\begin{array}{l}\text { Kalite } \\
\text { Değerlendirme } \\
\text { Puan Ortalaması }\end{array}$ \\
\hline $\begin{array}{l}\text { Köksal vd., } \\
\text { (1999) }\end{array}$ & $\begin{array}{l}\text { Cerrahpaşa Tıp Fakültesi } \\
\text { Öğrencilerinin Tıp Eğitimi } \\
\text { ve Mezuniyet Sonrası İle } \\
\text { İlgili Tutumları }\end{array}$ & $\begin{array}{l}\text { Öğrencilerin tıp eğitimi ve } \\
\text { mezuniyet sonrası ile ilgili } \\
\text { düşüncelerini saptamak }\end{array}$ & $\begin{array}{l}\text { Cerrahpaşa Tıp Fakültesi } \\
2-3-4-5 \text { ve } 6 \text {. sinıflardan } \\
\text { toplam } 1.340 \text { öğrenci }\end{array}$ & $\begin{array}{l}\text { Maddi tatmin, Tek branşta uzman- } \\
\text { laşma isteği, Daha iyi hekimlik } \\
\text { yapmak, İgili uzmanlık dalını } \\
\text { sevmek, Akademik kariyer yap- } \\
\text { mak, Pratisyen hekimliğin önemsiz } \\
\text { olması, Mesleki ve manevi tatmin. }\end{array}$ & 9,3 \\
\hline $\begin{array}{l}\text { Kara vd., } \\
(2014)\end{array}$ & $\begin{array}{l}\text { Analysis of Opinions } \\
\text { Regarding Medical Speci- } \\
\text { alty Selection Examination } \\
\text { and Career Choices of 5th } \\
\text { and 6th Grade Medical } \\
\text { Students from Düzce } \\
\text { University, Turkey }\end{array}$ & $\begin{array}{l}\text { Düzce Üniversitesi Tıp } \\
\text { Fakültesi öğrencilerinin } \\
\text { branş tercihleri ve TUS'a } \\
\text { ilişkin bakışlarının ince- } \\
\text { lenmesi }\end{array}$ & $\begin{array}{l}\text { Düzce Üniversitesi Tıp } \\
\text { Fakültesi 5. ve 6. sinıflar- } \\
\text { dan toplam } 101 \text { öğrenci }\end{array}$ & $\begin{array}{l}\text { Eğitim sonrası aile ve özel yaşam } \\
\text { üzerine etkileri, Akademik kariyer } \\
\text { yapma isteği, Çalışma koşulları, } \\
\text { Risk düzeyi, Alanı özellikleri. }\end{array}$ & 8,0 \\
\hline $\begin{array}{l}\text { Dikici vd., } \\
(2008)\end{array}$ & $\begin{array}{l}\text { Factors Affecting Choice } \\
\text { of Specialty Among First- } \\
\text { year Medical Students of } \\
\text { Four Universities in } \\
\text { Different Regions of } \\
\text { Turkey }\end{array}$ & $\begin{array}{l}\text { Tıp öğrencilerinin aile } \\
\text { hekimliği uzmanlık seçi- } \\
\text { mini etkileyen faktörler }\end{array}$ & $\begin{array}{l}19 \text { Mayıs, Karadeniz } \\
\text { Teknik, Adnan Menderes } \\
\text { ve Kocaeli Üniversitesin- } \\
\text { den } 770 \text { tıp fakültesi } 1 . \\
\text { sinıf öğrencisi }\end{array}$ & $\begin{array}{l}\text { Maddi getiri ve prestij, Kişisel } \\
\text { gelişim, Hastalara daha fazla } \\
\text { faydalı olma isteği, Şehirde yaşama } \\
\text { isteği, Kolay olması, Kişisel İlgi. }\end{array}$ & 11,0 \\
\hline $\begin{array}{l}\text { Tekin, } \\
\text { Güneş ve } \\
\text { Türkol, } \\
\text { (2013) }\end{array}$ & $\begin{array}{l}\text { İnönü Üniversitesi Tıp } \\
\text { Fakültesi Öğrencilerinin } \\
\text { Trpta Uzmanlık Tercihleri } \\
\text { ve Etkileyen Faktörler }\end{array}$ & $\begin{array}{l}\text { İnönü Üniversitesi Tıp } \\
\text { Fakültesi öğrencilerinin } \\
\text { mezuniyet sonrası yaşam- } \\
\text { larında önemli yeri olan } \\
\text { TUS tercihleri ve etkileyen } \\
\text { faktörleri değerlendirmek }\end{array}$ & $\begin{array}{l}\text { İnönü Üniversitesi } 1-2-3- \\
4-5 \text { ve } 6 . \text { sinuflardan } \\
\text { toplam } 563 \text { tıp fakültesi } \\
\text { öğrencisi }\end{array}$ & $\begin{array}{l}\text { Maddi getiri, Mesleki kariyer } \\
\text { fırsatı, Rahat olması, Nöbet sayısı, } \\
\text { Malpraktis riski, Toplumun bakışı. }\end{array}$ & 10,0 \\
\hline
\end{tabular}

798 • OPUS @ Uluslararası Toplum Araştırmaları Dergisi 


\begin{tabular}{|c|c|c|c|c|c|}
\hline $\begin{array}{l}\text { Ergin vd., } \\
(2011)\end{array}$ & $\begin{array}{l}\text { Tip Fakültesi Öğrencilerin } \\
\text { Mezuniyet Sonrası Kari- } \\
\text { yer Seçimi ve Etkileyen } \\
\text { Faktörler }\end{array}$ & $\begin{array}{l}\text { Pamukkale Üniversitesi } \\
\text { Tıp Fakültesi öğrencileri- } \\
\text { nin mezuniyet sonrası } \\
\text { kariyer seçimi ve bu } \\
\text { kariyer seçimini etkileyen } \\
\text { faktörleri araştırmak }\end{array}$ & $\begin{array}{l}\text { Pamukkale Üniversitesi } \\
1,3 \text { ve } 6 . \text { sinflardan } \\
\text { toplam } 203 \text { tıp fakültesi } \\
\text { öğrencisi }\end{array}$ & $\begin{array}{l}\text { Maddi olanaklar, Mesleki tatmin, } \\
\text { Prestij, Akademik kariyer fırsatı, } \\
\text { Toplumun gözündeki rol, Şehirde } \\
\text { çalışma isteği. }\end{array}$ & 9,3 \\
\hline $\begin{array}{l}\text { Göktaş- } \\
\text { Düzyol, } \\
\text { (2017) }\end{array}$ & $\begin{array}{l}\text { Tıp Fakültesi Son Sınıf } \\
\text { Öğrencilerinin Mezuniyet } \\
\text { Sonrası ile İlgili Düşünce- } \\
\text { leri, Kariyer Seçimleri ve } \\
\text { Etkileyen Faktörler }\end{array}$ & $\begin{array}{l}\text { Tıp Fakültesi son sınıf } \\
\text { öğrencilerinin mezuniyet } \\
\text { sonrası ile ilgili düşüncele- } \\
\text { ri, kariyer seçimleri ve } \\
\text { etkileyen faktörleri ince- } \\
\text { lemek }\end{array}$ & $\begin{array}{l}\text { Akdeniz Üniversitesi } 6 . \\
\text { sinıftan } 183 \text { tıp fakültesi } \\
\text { öğrencisi }\end{array}$ & $\begin{array}{l}\text { Kişisel ilgi, TUS puanı, Nöbet } \\
\text { durumu, Çalışma saatleri, Maddi } \\
\text { getiri, Malpraktis riski. }\end{array}$ & 9,0 \\
\hline $\begin{array}{l}\text { Açıkgöz } \\
\text { vd., } \\
\text { (2019) }\end{array}$ & $\begin{array}{l}\text { Tip Öğrencilerinde Uz- } \\
\text { manlaşma Eğilimi, Uz- } \\
\text { manlı Alan Seçimi ve } \\
\text { Etkileyen Faktörler }\end{array}$ & $\begin{array}{l}\text { Tip öğrencilerinin kariyer } \\
\text { planlamaları ve etkileyen } \\
\text { faktörleri değerlendirmek }\end{array}$ & $\begin{array}{l}\text { Zonguldak Bülent Ecevit } \\
\text { Üniversitesi 1-2-3-4-5 ve } \\
6 . \text { sinflardan } 798 \text { tıp } \\
\text { fakültesi öğrencisi }\end{array}$ & $\begin{array}{lrr}\text { Kişisel ilgi/yetenek, } & \text { Uzmanlık } \\
\text { alanının özellikleri, } & \text { Dersle- } \\
\text { rin/stajların etkisi, } & \text { Toplumun } \\
\text { algısı, Maddi getiri, } & \text { Cinsiyete } \\
\text { uygunluk, Uzmanlık eğitimi } \\
\text { sonrası yaşam tarzı, Nöbet sayısı. }\end{array}$ & 10,3 \\
\hline $\begin{array}{l}\text { Çetin, } \\
\text { Çimen ve } \\
\text { Türk, } \\
(2009)\end{array}$ & $\begin{array}{l}\text { Postgraduate Expectations } \\
\text { of the Graduates of A } \\
\text { Medical School in Turkey }\end{array}$ & $\begin{array}{l}\text { Tip Fakültesi öğrencileri- } \\
\text { nin mezuniyet sonrası } \\
\text { beklentileri ve TUS sınavı- } \\
\text { na yaklaşımlarını belirle- } \\
\text { mek }\end{array}$ & $\begin{array}{l}\text { GATA } 1-2-3-4-5 \text { ve } 6 . \\
\text { sinuflardan } 523 \text { tıp fakül- } \\
\text { tesi öğrencisi }\end{array}$ & 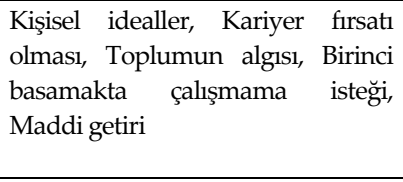 & 10,0 \\
\hline $\begin{array}{l}\text { Açık vd., } \\
(2002)\end{array}$ & $\begin{array}{lr}\text { Fırat Üniversitesi Tıp } \\
\text { Fakültesi Öğrencilerinin } \\
\text { Tıp Eğitimi Ve Mezuniyet } \\
\text { Sonrası Hakkındaki } \\
\text { Düşünceleri }\end{array}$ & $\begin{array}{l}\text { Fırat Üniversitesi T1p } \\
\text { Fakültesi öğrencilerinin tıp } \\
\text { eğitimi ve mezuniyet } \\
\text { sonrası ile ilgili düşüncele- } \\
\text { rini saptamak }\end{array}$ & $\begin{array}{l}\text { Fırat Üniversitesi } 1-2-3-4- \\
5 \text { ve } 6 . \text { sinıflardan } 488 \text { tıp } \\
\text { fakültesi öğrencisi }\end{array}$ & $\begin{array}{l}\text { Maddi tatmin, Tek branşta uzman- } \\
\text { laşma isteği, Daha iyi hekimlik } \\
\text { yapmak, Uzmanlık dalını sevmek, } \\
\text { Akademik kariyer yapmak, Pratis- } \\
\text { yen hekimliğin önemsiz olması, } \\
\text { Mesleki tatmin. }\end{array}$ & 9,7 \\
\hline
\end{tabular}


Tablo 1'de belirlenen çalışmalar içerisinde uzmanlık tercihlerini etkileyen faktörler yanında; tıp fakültesi tercih nedenleri, branş tercihleri, TUS'a bakış, uzmanlığa bakış, tıp eğitimi ile ilgili düşünceler gibi farklı yönlerde çıtılar da bulunmaktadır, ancak derlemede sadece uzmanlık seçimini etkileyen faktörler ve tercih edilen alanlar göz önüne alınmıştır. Çalışmalar incelendiğinde; Köksal ve arkadaşlarının (1999, s.254-257) çalışmasında, katılımcıların $\% 89,6$ 'sı mezuniyet sonrası uzmanlık eğitimi almak istediklerini belirtmişlerdir. Öğrenciler tercih edecekleri uzmanlık dallarını etkileyen nedenler olarak maddi tatmin $(\% 24,8)$, tek branşta uzmanlaşmak $(\% 11,8)$, daha iyi hekimlik yapmak (\%12,5), ilgili uzmanlık dalını sevmek (\%11,7), akademik kariyer yapmak $(\% 10,2)$, pratisyen hekimliğin önemsiz olması $(\% 7,1)$, mesleki tatmin $(\% 8,1)$, manevi tatmin $(\% 3,9)$, toplumun uzmanlara güven duyması $(\% 2,3)$ ve diğer nedenler $(\% 7,6)$ şeklinde karşımıza çıkmaktadır. Kara ve arkadaşlarının (2014: s.15-17) yürütmüş olduğu çalışmada, TUS tercihlerini en çok etkileyen 5 neden olarak; eğitim sonrası aile ve özel yaşam üzerine etkileri $(\% 48,5)$, akademik kariyer yapma isteği $(\% 13,9)$, çalışma koşulları $(\% 8,9)$, risk ve sorumluluk düzeyi $(\% 7,9)$, eğlence, ilginçlik veya monotonluk ve sıkıcı özellikleri $(\% 4)$ ve diğer nedenler $(\% 16,8)$ şeklinde ortaya çımiştır.

Dikici ve arkadaşları (2008: s.417), çalışmalarında birinci sınıflar üzerinde araştırma yapmış ve uzmanlaşma nedenleri olarak; maddi getiri ve prestij $(\% 30,54)$, kişisel gelişim $(\% 20,78)$, hastalara daha fazla faydalı olma isteği $(\% 17,85)$, şehirde yaşama isteği $(\% 4,46)$, kolay olması $(\% 1,68)$, kişisel ilgi $(\% 1,68)$ ve diğer nedenler $(\% 1,68)$ şeklinde oluşmuştur. Çetin, Güneş ve Türkol'un (2013: s.8-9) İnönü Üniversitesi'nde yürüttüğü çalışmada, uzmanlık tercihini etkileyen faktörler olarak; maddi getiri, aile baskısı, malpraktis riski, nöbet sayısı, toplumun bakışı, bilimsel araştırma ve akademik kariyer şeklinde oluşmuştur. Ayrıca ortaya koyma üzere tercih edilen alanın etkileyen faktörler ile karşılaştırmaları da yapılmış anlamlı farklılıklar bulunamamıştır.

Ergin ve arkadaşlarının (2011, s.31-32) Pamukkale Üniversitesi'ne yürütmüş oldukları çalışmada, örneklem içindeki 1., 3. ve 6. sınıf öğrencilerinin neredeyse tamamı uzman hekimliği istediklerini belirtmişlerdir. Uzmanlık tercihini etkileyen faktörler olarak ise; maddi olanaklar, mesleki tatmin, şehirde çalışma isteği, toplumun algısı, prestij, akademik kariyer, uzman hekimliğin kolay olması ve diğer nedenler şeklinde her sınıftan öğ- 
renciler arasında tercihleri belirleyen en önemli faktörler olarak karşımıza çıkmaktadır. Göktaş-Dörtyol (2017, s.15-16) tarafından yapılan araştırmada ise örneklemdeki öğrencilerin \%92,9'u uzmanlı yapmak istediklerini belirtmiştir. Uzman olmanın gerekliliği konusundaki düşünceleri; mesleki tatmin, kariyer yapma, daha çok kazanç elde etme ve statü elde etme olarak belirtmişlerdir. Öğrenciler uzmanlık seçimini etkileyen faktörler olarak ise; kişisel ilgi $(\% 80,3)$, TUS puanı $(\% 72,1)$, nöbet durumu $(\% 59,0)$, çalışma saatlerinin yoğunluğu $(\% 57,9)$, maddi getiri $(\% 51,9)$, malpraktis riski $(\% 42,6)$ şeklinde oluşmuştur.

Açkgöz ve arkadaşları (2019: s.120-124) tarafından Zonguldak Bülent Ecevit Üniversitesinde yapılan çalışmada; örnekleme dâhil olan öğrencilerin $\% 85,7$ 'si uzman olmak istediklerini belirtmişlerdir. Öğrenciler uzmanlık seçimini etkileyen faktörler olarak; kişisel ilgi/yetenek (\%46,0), uzmanlık alanının özellikleri (\%45), ailedeki/yakındaki hastalara yardımcı olmak $(\% 33,9)$, derslerin/stajların etkisi $(\% 33,2)$, cinsiyete uygunluk $(\% 30,5)$, toplumun algısı $(\% 30,4)$, maddi getiri $(\% 29,2)$, uzmanlı alanındaki tedavi sonuçlarının gözle görünür olması $(\% 28,0)$, uzmanlık eğitimi sonrası yaşam tarzı (\%26,7), nöbet sayısı (\%26,5), malpraktis riskinin azlığı (\%23) ve diğerleri şeklinde karşımıza çıkmıştır. Çetin, Çimen ve Türk (2009: s.69) tarafından yapılan araştırmada, örneklem dâhilindeki öğrencilerin \%95,2'si uzmanlık yapmak istediklerini belirtmişlerdir. Uzmanlık tercihlerini etkileyen faktörler olarak ise; kişisel idealler $(\% 27,0)$, mesleki kariyer kaygısı $(\% 23,7)$ ve pratisyen hekimliğin toplumda değerinin olmaması $(\% 19,5)$, birinci basamakta çalışmama isteği $(\% 16,4)$, maddi getiri $(\% 13,4)$ şeklinde ortaya çımiştır.

Açık ve arkadaşları (2002: s.198-199) tarafından Fırat Üniversitesi'nde yapılan çalışmada, öğrencilerin \%92'si mezuniyet sonrası uzmanlık yapmak istediğini belirtmiştir. Öğrenciler uzmanlık tercihlerini belirleyen faktörler olarak ise; maddi açıdan tatmin olmak $(\% 29,1)$, tek branşta uzmanlaşmak $(\% 28,3)$, daha iyi hekimlik yapmak $(\% 37,7)$, bu uzmanlık dalını sevmek $(\% 63,5)$, akademik kariyer yapmak $(\% 29,5)$, pratisyen hekimliğin önemsiz olması (\%15,4), mesleki açıdan tatmin olmak (\%30,9), manevi açıdan tatmin olmak (\%30,7), toplumun uzmanlara güven duyması (\%19,3), serbest çalışma olanağının olması $(\% 18,2)$, işsiz kalmamak $(\% 6,8)$ ve diğer nedenler $(\% 2,9)$ şeklinde oluşmuştur. Tüm bu bulguların yanında derlemedeki tüm 
çalı̧̧malarda, öğrencilerin ezici çoğunluğunun uzman olmak istediklerini belirtmişlerdir.

Belirlenen 9 adet çalışmanın yukarıda sunulan sonuçları, tarafımızdan uzmanlık eğitimi öncesi ve uzmanlık eğitimi sonrası şeklinde iki kategori oluşturularak tercihleri etkileyen faktörler Tablo 2'de bir araya getirilmiştir. Kategorilerin belirlenmesinde; uzmanlık eğitimi öncesi kategorisinde ele alınan faktörler, tıp eğitimi sırasında öğrencilerin etkilendiği durumlardan yola çıkılarak seçilmiştir. Uzmanlık eğitimi sonrası kategorisinde yer alan faktörler ise; öğrencilerin uzmanlık yapacakları döneme ilişkin düşüncelerini gösteren faktörleri kapsamaktadır. Çalışmalardan elde edilen sonuçlardan hareketle uzmanlık eğitimi öncesi 11 adet faktör ve uzmanlık eğitimi sonrası 11 adet faktör bulunmuştur. Bu şekilde daha bütüncül bir bakış açısı elde edilmeye çalışılmıştır. Tablo 2 'de ayrıca faktörlerin hangi çalışmalarda yer aldığı ve ilgili faktörün kaç çalışmada ortaya çıktığı da belirtilmiştir.

Tablo 2. Incelenen Çalışmalardaki Tercihleri Etkileyen Faktörlerin Sınıflandırılması

\begin{tabular}{|c|c|c|c|}
\hline $\begin{array}{l}\text { Tercihleri Etkileyen } \\
\text { Faktörlerin Kategorisi }\end{array}$ & $\begin{array}{l}\text { Tercihleri } \\
\text { Etkileyen Faktör }\end{array}$ & Çalışma Adı & $\begin{array}{l}\text { Çalışma } \\
\text { Sayısı }\end{array}$ \\
\hline \multirow{11}{*}{$\begin{array}{l}\text { Uzmanlık } \\
\text { Eğitimi } \\
\text { Öncesi }\end{array}$} & $\begin{array}{l}\text { Uzmanlık dalına } \\
\text { olan ilgi/yetenek }\end{array}$ & $\begin{array}{l}\text { Köksal vd., 1999; Dikici vd., 2008; Göktaş- } \\
\text { Düzyol, 2017; Açıkgöz vd., 2019; Açık } \\
\text { vd., } 2002\end{array}$ & 5 \\
\hline & $\begin{array}{l}\text { Hastalara daha fazla } \\
\text { faydalı olma isteği }\end{array}$ & Dikici vd., 2008 & 1 \\
\hline & Ders ve stajlarm etkisi & Açıkgöz vd., 2019 & 1 \\
\hline & TUS Puanı & Göktaş-Düzyol, 2017 & 1 \\
\hline & Toplumun algısi/bakışı & $\begin{array}{l}\text { Tekin, Güneş ve Türkol, 2013; Ergin vd., } \\
\text { 2011; Açıkgöz vd., 2019; Çetin, Çimen ve } \\
\text { Türk, } 2009\end{array}$ & 4 \\
\hline & Cinsiyete uygunluk & Açıkgöz vd., 2019 & 1 \\
\hline & $\begin{array}{l}\text { Uzmanlik alanının } \\
\text { özellikleri }\end{array}$ & Kara vd., 2014; Açıkgöz vd., 2019 & 2 \\
\hline & Kişisel idealler & Çetin, Çimen ve Türk, 2009 & 1 \\
\hline & $\begin{array}{l}\text { Birinci basamakta } \\
\text { çalışmama isteği }\end{array}$ & Çetin, Çimen ve Türk, 2009 & 1 \\
\hline & $\begin{array}{l}\text { Tek branşta } \\
\text { uzmanlaşma } \\
\text { isteği }\end{array}$ & Köksal vd., 1999; Açık vd., 2002 & 2 \\
\hline & Aile isteği/baskısı & $\begin{array}{l}\text { Tekin, Güneş ve Türkol, 2013; Ergin vd., } \\
\text { 2011; Göktaş-Düzyol, 2017; Açıgöz vd., } \\
2019\end{array}$ & 4 \\
\hline $\begin{array}{l}\text { Uzmanlık Eğitimi } \\
\text { Sonrası }\end{array}$ & Maddi tatmin & $\begin{array}{l}\text { Köksal vd., 1999; Dikici vd., 2008; Tekin, } \\
\text { Güneş ve Türkol, 2013; Ergin vd., 2011; } \\
\text { Göktaş-Düzyol, 2017; Açıkgöz vd., 2019; } \\
\text { Çetin, Çimen ve Türk, 2009; Açk vd., } \\
2002\end{array}$ & 8 \\
\hline
\end{tabular}




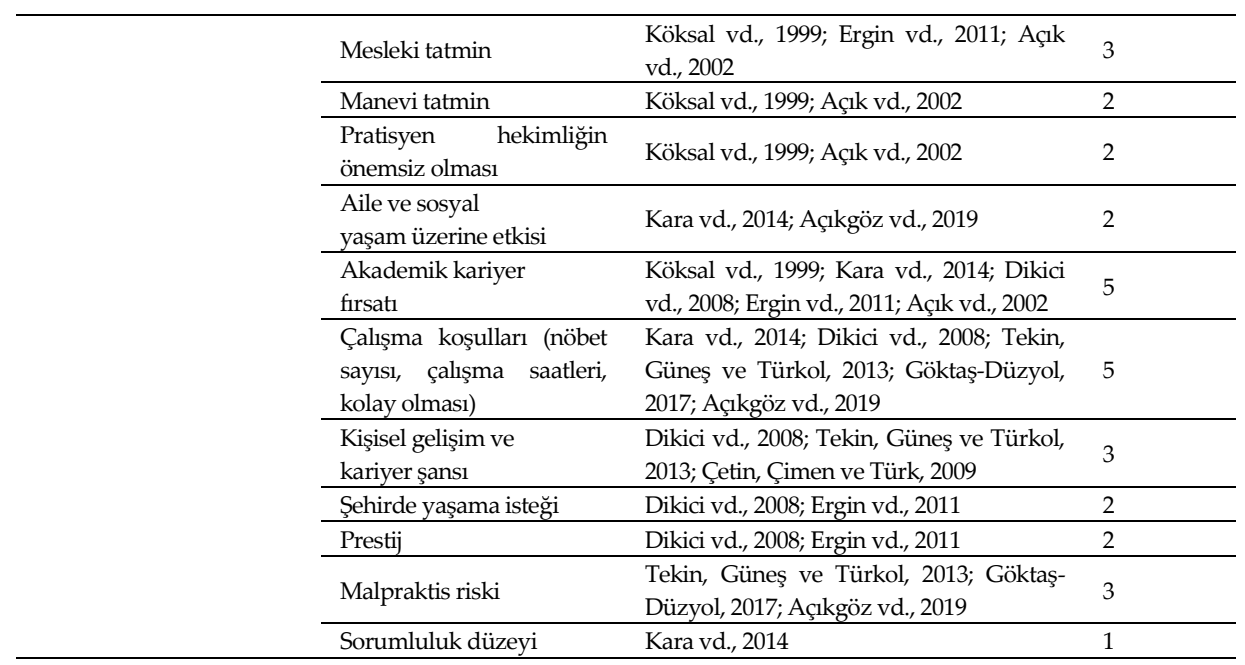

Tablo 2'de görüldüğü üzere; uzmanlık eğitimi öncesi kategorisinde yer alan en önemli faktörler uzmanlık dalına olan ilgi/yetenek (5 çalışma) (Köksal vd., 1999; Dikici vd., 2008; Göktaş-Düzyol, 2017; Açıkgöz vd., 2019; Açık vd., 2002), toplumun algisı/bakışı (4 çalışma) (Tekin, Güneş ve Türkol, 2013; Ergin vd., 2011; Açıkgöz vd., 2019; Çetin, Çimen ve Türk, 2009), aile isteği/baskısı (4 çalışma) (Tekin, Güneş ve Türkol, 2013; Ergin vd., 2011; GöktaşDüzyol, 2017; Açıkgöz vd., 2019) olarak karşımıza çıkmaktadır. Uzmanlık eğitimi sonrası süreçte ise öğrenciler tarafından belirtilen en önemli faktörler; maddi tatmin (8 çalışma) (Köksal vd., 1999; Dikici vd., 2008; Tekin, Güneş ve Türkol, 2013; Ergin vd., 2011; Göktaş-Düzyol, 2017; Açıkgöz vd., 2019; Çetin, Çimen ve Türk, 2009; Açık vd., 2002), çalışma koşulları (nöbet sayısı, çalışma saatleri, kolay olması) (5 çalışma) (Kara vd., 2014; Dikici vd., 2008; Tekin, Güneş ve Türkol, 2013; Göktaş-Düzyol, 2017; Açıkgöz vd., 2019), akademik kariyer fırsatı (5 çalışma) (Köksal vd., 1999; Kara vd., 2014; Dikici vd., 2008; Ergin vd., 2011; Açık vd., 2002), mesleki tatmin (3 çalışma) (Köksal vd., 1999; Ergin vd., 2011; Açık vd., 2002), kişisel gelişim ve kariyer şansı (3 çalışma) (Dikici vd., 2008; Tekin, Güneş ve Türkol, 2013; Çetin, Çimen ve Türk, 2009), malpraktis riski (3 çalışma) (Tekin, Güneş ve Türkol, 2013; Göktaş-Düzyol, 2017; Açıgöz vd., 2019) olarak ortaya çıkmıştır.

Görüldügü üzere uzmanlı eğitimi sonrası kategorisinde yer alan faktörler öğrenciler tarafından daha fazla şekilde belirtilmiştir. Özellikle maddi 
tatmin bir çalışma hariç tüm çalışmalarda öğrencilerin tercihini etkilediği görülmüştür. Çalışma koşulları, akademik kariyer fırsatı ve şehirde yaşama isteği de öğrenciler açısından önemli faktörler olarak ortaya çıkmıştır. Derlemede ele alınan çalışmalarda en dikkat çekici bulgulardan birisi de 2013, 2017, ve 2019 yılında yapılan çalışmalarda (Tekin, Güneş ve Türkol, 2013; Göktaş-Düzyol, 2017; Açıkgöz vd., 2019) önceki yıllardaki çalışmalardan farklı olarak malpraktis riskinin azlığı seçeneği olmuştur. Öğrencilerin son yıllarda malpraktis riskini göz önüne alarak tercih yapmaya başladıkları ortaya çıkmaktadır. 2014 yılında Kara ve arkadaşlarının çalışmasındaki sorumluluk düzeyi de bu sonucu doğrular niteliktedir (Kara vd., 2014). Malpraktis riskinin azlığ ile aile ve sosyal yaşam üzerine etkisi, sorumluluk düzeyi ve çalışma koşulları bir arada göz önüne alındığında; öğrencilerin aslında çalışma koşulları daha esnek, malpraktis açısından daha az riskli olan daha rahat bölümleri seçme yoluna girdikleri ortaya çımaktadır.

\section{Tartışma}

TUS ülkemizde sağlık hizmet sunumunun en önemli parçaları olan hekimlerin geleceğini belirleyen bir konumdadır. Bu kapsamda, ülkemizdeki sağlık hizmetinin en önemli köşe taşlarından olan hekimlerin uzmanlık tercihleri oldukça önemli bir yere sahiptir. Bu önemli süreçte, öğrencilerin tercihlerini etkileyen faktörlerin ortaya çıarılması, incelenmesi ve elde edilen bulgulara göre politikalar geliştirilmesi oldukça önemlidir. Özellikle son dönemde uzmanlık alan tercihlerindeki değişim bu konuyu daha önemli hale getirmiştir. Bu konuda yapılan çalışmalara bakıldığında; Kaya ve arkadaşları (2014, s.57-58) Tam Gün Yasası ve malpraktis davalarının artışı kadın hastalıkları ve doğum ve genel cerrahi gibi riskleri fazla olan bölümlerin tercih edilebilirliğini azalttığını belirtmişlerdir. Bunun yanında dahili bölümlerde ise çeşitli sebepler bir artışın olduğunu vurgulamışlardır. Kasap ve arkadaşları tarafından yapılan çalışmada ise 2009-2013 yılları arasında aile hekimliği, dermatoloji, FTR, nükleer tıp gibi alanların puanlarının yükseldiği, cerrahi alanların ise puanlarının önemli derecede düştüğü ortaya çımıştır. Bunun yanında dava edilme riski yüksek olan 6 uzmanlık dalının (acil tıp, beyin cerrahisi, kadın doğum, genel cerrahi, ortopedi ve pediatri) puanlarının gözle görülür şekilde düştüğünü belirtmişlerdir. İlgili alanlara tercih- 
lerin azalmasının önemli bir nedeni de artan şiddet olayları olduğunu belirtmişlerdir (Kasap vd., 2015, s.35-37).

Tercihlerin yönünün değişimine ilişkin Sağlık Bakanı Dr. Fahrettin Koca 20 Şubat 2019 tarihli bir toplantıda yaptığı açıklamada mevcut tercih sıralamalarından örnekler vermiş (daha çok dâhili branşların tercih edildiğini ve cerrahi branşlarının sonlarda olduğunu belirtmiştir) ve şu şekilde devam etmiştir; "...Bu tabloda gördüğümüz çok açık ve net. Özellikle riski düşük olan, hastayla fazla meşgul olunmayan; cildiye, fizik tedavi ve radyoloji gibi branşlarm daha çok tercih edildiği, ama beyin cerrahisi gibi kalp damar cerrahisi gibi kadın doğum gibi meşakkatli, sorunlu, adli sorunları da beraberinde olan branşlarm tercihinin daha aşağılarda olduğunu görüyoruz. Bunun ülke için hayra alamet olmadığın hepimiz söyleyebiliriz. Bu doğru bir şey değil. En önemli, kendinizi emanet ettiğiniz bölümlerle ilgili olsa da olur diye tercih edildiğini görüyoruz." (Koca, 2019). Sağlık Bakanı'nın açıklamaları da tercihleri etkileyen faktörlerin oldukça önemli bir konumda olduğunu göstermiştir. Bu derlemede seçilen çalışmalarda da tercih edilen alanlarla ilgili olarak; sınıf arttıkça cerrahi alanın tercih edilmesinin azalması (Ergin vd.,2011, Açıkgöz vd., 2019), sadece 1999 yılında Cerrahpaşa Tıp Fakültesi'nde yapılan çalışma hariç hiçbir çalışmada Genel Cerrahi alanının olmaması ve dahiliye bölümlerinin daha çok yer alması sonuçları güçlü kanıtlar olarak karşımıza çıkmaktadır.

Derlemede ele alınan çalışmalara bakıldığında, öncelikle çeşitli yönlerden benzerlik gösterse de tercihleri etkileyen faktörlerin ortaya konulmasında bir bütünlük olmadığı görülmektedir. Bunun sebebi çalışmalardaki ölçekler veya sorulardaki farklılıklar olarak karşımıza çıkmaktadır. Ancak çalışmaların elde ettiği sonuçlar bakımından çeşitli ülkeler ile yaptıkları karşılaştırmalarda büyük uyum olduğu göze çarpmaktadır. Örnek olarak; Kara ve arkadaşları çalışmasındaki tercihleri etkileyen faktörlerin Seetharaman ve Logaraj ile Dorsey ve diğerlerinin çalışmaları ile benzerlik gösterdiğini belirtmiştir (Kara vd., 2014, s.17; Dorsey ve Logaraj, 2005, Seetharaman vd., 2012). Benzer şekilde Dikici ve arkadaşları çalışmalarının Pakistan, Tayvan ve ABD'de yapılan çalışmalar ile benzerlik gösterdiğini belirtmişlerdir (Dikici vd., 2008, s.418; Huda ve Yousuf, 2006; Chang vd. 2006; Newton, Grayson ve Thompson, 2004). Derlemedeki diğer tüm çalışmalar da diğer ülkelerde yürütülen çalışmalar ile tercihleri etkileyen faktörler konusunda benzerlikler olduğunu kanıtlamışlardır. 
Derlemede yer alan çalışmaların genellikle bir üniversitede tıp fakültesinde öğrenim gören öğrenciler üzerinde yapıldığı (Dikici ve arkadaşlarının yapmış olduğu çalışma hariç) ve örneklemlerin genellikle ilgili üniversite ile sınırlı kaldığı görülmektedir. Bu kapsamda yapılacak çalışmaların farklı üniversitelerde ve daha fazla öğrencileri kapsayacak şekilde yapılması daha büyük verileri elde etmeyi sağlayacak daha genel ve kapsayıcı yorumlar yapılmasını kolaylaştıracaktır.

\section{Sonuç}

Yukarıda elde edilen kanıtlar ve Sağlık Bakanı tarafından yapılan açılamalar göz önüne alındığında; günümüzde uzmanlık alan tercihlerinde gözle görülür bir değişim yaşandığı ve uzmanlık tercihini etkileyen birçok faktörün var olduğu görülmektedir. Özellikle uzmanlık eğitimi sonrası yaşam, gelir ve malpraktis durumları ögrencilerin tercihlerinde önemli derecede etkili olmaktadır. Derlemeden elde edilen kanıtlar ışığında öneriler geliştirilecek olursa;

- Sağlık Bakanlığ bünyesinde bir çalışma grubu oluşturulması, ilgili çalışma grubunun ve konu ile ilgili olan paydaşlarm bir araya gelmesinin sağlanmasl,

- Konuya ilişkin yapılan çalşmalar göz önüne alan ve çalışma grubunun tartışmaların içerecek şekilde; tercihleri etkileyen veya etkileyebilecek faktörleri bir arada sunan bir anket formu oluşturmasl,

- Oluşturulan anket formunun yapilacak TUS tercih(ler)i strasinda uzmanlık alanı tercih eden adaylara velveya tıp fakültesi ögrrencilerine yönelik olarak uygulanmasının sağlanması, ulusal çapta uzmanlık tercihine dayah verilerin toplanmasl,

- Toplanan verilerin ilgili çalışma grubu ve sistem içindeki paydaşlar ile birlikte ele alınarak çeşitli çözüm önerilerinin geliştirilmesi ve kanıta dayalı politikalar oluşturulması önerilmektedir.

Bunun yanında tercih edilme durumu azalan cerrahi branşlara sunulan maddi olanakların artırılması, malpraktis riskine karşı hekimlerin sigortalanması gibi daha elle tutulur gözle görülür politikaların benimsenmesi önerilmektedir. Bu politikaların benimsenmesi hem ilginin azaldığı branşlardaki mevcut hekimlerin daha rahat olmasını ve kendilerini güvende hissetmesini sağlayacak hem de ilgili bölümlerin tercih edilebilirliğini artıracağ1 düşünülmektedir. 


\title{
EXTENDED ABSTRACT
}

\section{Systematic Review On Factors Affecting Medical Students Preferences In Medical Specialization}

\author{
İbrahim Hüseyin Cansever - Aslı Metin - Merve Kişi \\ Süleyman Demirel University
}

The choice of profession is an important phenomenon that affects the individual's life in every way. The profession of medicine requires a certain education like all other professions. The profession of medicine can be done by obtaining the title of medical doctor after undergraduate education in medical faculties; however, according to the result of the specialization exam entered after the undergraduate education, specialist medicine can be performed with specialization training that covers specialization in the preferred field. The choice of areas of speciality has an important role in the functioning of the health systems of the countries and the services needed by the society. As in almost every country, Turkey also has experienced great transformation in the selection of areas of expertise. The aim of the study reveals the preferences specialty in medicine that change over time and the reasons affecting them. Therefore, the studies which examining the factors affecting the choice of expertise in the medical students in Turkey compiled. Thus, it was aimed to make a general evaluation and develop an evidence-based policy proposal regarding the results achieved. Systematic review method was used in this study. For this purpose in Turkish and English languages, ULAKBIM, Google Scholar, Science Direct database in "Examination for specialty in medicine", "Student" and "Turkey" search using keywords have been made. As the inclusion criteria; It was determined to be published in a refereed journal, to be of quantitative nature, to have medical students in the sample group, and to include specialist preferences for the after graduate period and nine studies compatible with the determined criteria were included in the review. In the quality evaluation of nine studies included in the review, the evaluation criteria proposed by Polit and Beck (2009) were used. It was evaluated by all authors based on the criteria for each study in the review and received a total value by giving a score of "1" 
in case of meeting these criteria and " 0 " in case of not meeting. As a result of this evaluation, the studies were given the highest 11 and the lowest 8 points. In order to reveal the harmony among the authors, a compliance analysis was performed in the SPSS program and the fleiss kappa value was found to be 0.561 (medium-good). In this review, the factors affecting the preferences of medical students were investigated and it was found that many factors affected the preferences of the students. The result factors were categorized as "before specialty education in medicine" and "after specialty education in medicine". This categorization has made it easier to see the results more clearly and to propose solutions. Before specialty education in medicine process, as the factors of the preferences of specialty, interest / talent in the field of specialization, the desire to be more beneficial to patients, the effect of lessons and internships, TUS score, perception/view of society and family, gender suitability, specialties of the field of study, personal ideals, desire not to work in primary care, desire to specialize in a single branch, desire / pressure has ben determined. After specialty education in medicine, as the factors of preferences in specialty, financial satisfaction, professional satisfaction, insignificant of general practitioners, impact on family and social life, academic career opportunity, working conditions conditions (number of shift, working hours, ease of working ), personal development, career chance, desire to live in the city, prestige, risk of malpractice and level of responsibility has ben determined. In the examination, it was observed that the factors in the post-specialty education category were stated more by the students. It has been observed that financial satisfaction affects students' preference in all studies except one study. Working conditions, academic career opportunities and desire to live in the city have also emerged as important factors for students. Associated with the results obtained from the compilation and in a similar way studies which in Turkey to address the exchange of specialty in medicine preference stated that particularly with the increase in malpractice lawsuits and more riskly sections like gynecology and obstetrics or general surgery reduce the choice of the sections. The scores of fields such as family practice, dermatology, physical medicine and rehabilitation and nuclear medicine have increased. However, the scores of six specialist branches (emergency medicine, neurosurgery, gynecology, general surgery, orthopedics and pediatrics) with high risk have decreased significantly. Regarding factors affecting preferences, all 
studies in the review were similar to those conducted in other countries. In addition, the studies discussed in the review show similarities with each other in various aspects; however, it was observed to differ in terms of scope and content. In the light of the evidence obtained from the review suggestions are presented; (1) Establishing a working group within the Ministry of Health, ensuring that the relevant working group and stakeholders come together, (2) Considering the work done on the subject and including the discussions of the working group; creating a questionnaire that presents factors that affect or may affect the preferences together, (3) Ensuring that the created questionnaire form is applied for candidates and / or medical students who prefer specialization during TUS preference(s) to be collected and gathering national data on choice of expertise, (4) Developing various solution proposals and developing evidence-based policies by handling the collected data together with the relevant working group and stakeholders in the system. In addition, it has been proposed to adopt more tangible policies such as increasing the financial opportunities offered to the surgical branches, the preference of which is decreasing, and insurance of physicians against malpractice risk.

\section{Kaynakça / References}

Açık, Y., Oğuzöncül, F., Polat, S. A., Güngör, Y. ve Güngör, L. (2002). Firat Üniversitesi Tıp Fakültesi öğrencilerinin tıp eğitimi ve mezuniyet sonrası hakkındaki düşünceleri. Toplum ve Hekim, 17(3), 195-201.

Açıkgöz, B., Ekemen, A., Zorlu, I., Aslından Yüksel, N. ve Ayoğlu, F.N. (2019). Tıp öğrencilerinde uzmanlaşma eğilimi, uzmanlık alan seçimi ve etkileyen faktörler. Mersin Üniversitesi Sağllk Bilimleri Dergisi, 12(1), 113-125.

Brown, D. (2002). The role of work and cultural values in occupational choice, satisfaction, and success: A theoretical statement. Journal of Counselling and Development, 80, 48-56.

Chang, P. Y., Hung, C. Y., Wang, K. L., Huang, Y. H. ve Chang, K. J. (2006). Factors influencing medical students' choice of specialty. Journal of the Formosan Medical Association, 105(6), 489-496.

Çetin, M., Çimen, M. ve Türk, Y.Z. (2009). Postgraduate expectations of the graduates of a medical school in Turkey, Akademik Dizayn Dergisi, 3(3), 65-70. 
Dikici, F. M., Yaris, F., Topsever, P., Muge Filiz, T., Serdar Gurel, F., Cubukcu, M., ve Gorpelioglu, S. (2008). Factors affecting choice of specialty among first-year medical students of four universities in different regions of Turkey. Croatian medical journal, 49(3), 415-420.

Dorsey, E.R., Jarjoura, D., Rutecki ve G.W. (2005). The influence of controllable lifestyle and sex on the specialty choices of graduating U.S. medical students: 1996-2003. Academic Medicine, 80(9), 791-796.

Ergin, A., Dikbaş, E., Bozkurt, A. İ., Atçeken, G., Gürbüz, H., Yılmaz, C., Çölbe, S.N., Taşcl, U., Güldamla, L. ve Demircan, H.İ. (2011). Tıp fakültesi öğrencilerin mezuniyet sonrası kariyer seçimi ve etkileyen faktörler, Tip Ĕ̆itim Dünyası, 32, 8-17.

Koca, F.(2019). Bir doktor adayı arkadaşımızın 'Neden tıptan mezun olanlar hastaları daha az görecekleri bölümleri tercih ediyor?' sorusu üzerine TUS'taki tercih stralamasinı paylaştık. @drfahrettinkoca, [Twitter]. https://twitter.com/drfahrettinkoca/status/1098174234751393793 adresinden erişilmiştir.

Fleiss, J.L. (2003). Statistical methods for rates and proportions. (3. Ed), John Wiley \& Sons Inc., New Jersey.

Dörtyol, B. G. (2017). Tip fakültesi son sinif öğrencilerinin mezuniyet sonrasi ile ilgili düşünceleri, kariyer seçimleri ve etkileyen faktörler. Tıp Eğitimi Dünyası, 16(50), 12-21.

Guraya, S. Y. ve Almaramhy, H. H. (2018). Mapping the factors that influence the career specialty preferences by the undergraduate medical students. Saudi journal of biological sciences, 25(6), 1096-1101.

Heckhausen, H. (1977). Achievement motivation and its constructs: A cognitive model. Motivation And Emotion, 1(4), 283-329.

Huda, N., ve Yousuf, S. (2006). Career preference of final year medical students of Ziauddin Medical University. Educ Health (Abingdon), 19(3), 345-53.

Kara, İ.H., Çelik, Z., Keyif, M.F., Demir, A. Baltacı, D. ve Mayda, A.S. (2014). Analysis of opinions regarding medical specialty selection examination and career choices of 5th and 6th grade medical students from Düzce University. Konuralp Tip Dergisi, 6(2), 11-18.

Kasap, H., Akar, T., Demirel, B., Dursun, A.Z., Sarı, S., Özkök, A. ve Aydemir, Ö. (2015). Tıbbi uygulama hatası riski yüksek olan uzmanlık dallarının tıpta uzmanlık sınavında tercih edilme önceliklerinin yıllara göre değişimi. Adli Tıp Bülteni, 20(1), 34-37. 
Kaya, A., Aktürk, Z., Çayır, Y. ve Taştan K. (2014). 2007-2013 arası tıpta uzmanlık sinavları: Bir trend analizi, Ankara Medical Journal, 14(2), 53-58.

Kılıç, S. (2015). Kappa Testi, Journal of Mood Disorders, 5(3), 142-144.

Köksal, S., Vehind, S., Tunçkale, A., Çerçen, A., Erginöz, E., Kaypmaz, A. ve Özbal, A. N. (1999). The anttitude of students of Cerrahpaşa School of Medicine on medicak education and postgraduated situation. Cerrahpaşa J Med, 30(4), 251-8.

Landis, J.R. ve Koch, G.G. (1977). The measurement of observer agreement for categorical data. Biometrics, 33(1), 159-174.

Newton, D. A., Grayson, M. S. ve Thompson, L. F. (2005). The variable influence of lifestyle and income on medical students' career specialty choices: data from two US medical schools, 1998-2004. Academic Medicine, 80(9), 809-814.

ÖSYM, (2019), 2019 tıpta uzmanlık eğitimi giriş sinavı başvuru kılavuzu, ÖSYM Sınav Hizmetleri Daire Başkanlığı, Ankara.

Polit, D.F. ve Beck, C.T. (2009). Literature reviews: Finding and reviewing research evidence. Essentials of Nursing Research: Appraising Evidence for Nursing Practice içinde (s.196-193). 7.Edition, Lippincott Williams and Wilkins, Philadelphia.

Sağlık Bakanlığı Tıpta Uzmanlık Kurulu (2018). Eğitim süreleri hakkında karar. Karar Yürürlük Tarihi: 03.01.2018.

Sağlık Personelinin Tazminat ve Çalışma Esaslarına Dair Kanun, Devlet Memurları Kanunu ve Tababet ve Şuabatı San'atlarının Tarzı İcrasına Dair Kanun ile Sağlık Bakanlığının Teşkilat ve Görevleri Hakkında Kanun Hükmünde Kararnamede Değişiklik Yapılmasına Dair Kanun. (2005). Kanun No:5371, Kabul tarihi: 21/06/2005.

Seetharaman N. ve Logaraj M. (2012). Why become a doctor? Exploring the career aspirations and apprehensions among interns in South India, $\mathrm{Na}$ tional Journal Research Com. Medical, 1(4), 178-241.

Skatova, A. ve Ferguson, E. (2014). Why do different people choose different university degrees? Motivation and the choice of degree. Frontiers in Psychology. 5(1244), 1-15.

Tekin, Ç., Güneş, G. ve Türkol, E. (2013). İnönü Üniversitesi Tip Fakültesi öğrencilerinin tıpta uzmanlık tercihleri ve etkileyen faktörler, İø̈n̈̈ Üniversitesi Sağllk Bilimleri Dergisi, 1, 5-10.

Yoney, H. ve Gogas-Yavuz, D. (2010). Tipta uzmanlık seçimi, İstanbul:Marmara Üniversitesi Yayınları Yayın No: 778. 


\section{Kaynakça Bilgisi / Citation Information}

Cansever, İ. H., Metin, A. ve Kişi, M. (2020). Tıp öğrencilerinin tıpta uzmanlık tercihlerini etkileyen faktörler üzerine sistematik derleme. OPUS-Uluslararası Toplum Araştırmaları Dergisi,16(27), 791812. DOI: 10.26466 -/opus.646193 